\title{
Raman spectra of gas mixtures in fluid inclusions: effect of quartz birefringence on composition measurement
}

\author{
Marie-Camille Caumon ${ }^{1 *}$, Alexandre Tarantola ${ }^{1}$, Wenjing Wang ${ }^{2}$ \\ ${ }^{1}$ Université de Lorraine, CNRS, GeoRessources Lab, BP 70239, F-54506 Vandœuvre-lès-Nancy, France ${ }^{2}$ College of Marine \\ Science and Technology, China University of Geosciences, 430074, Wuhan, China \\ *corresponding author: Marie-Camille Caumon marie-camille.caumon@univ-lorraine.fr
}

Published in Journal of Raman Spectroscopy 2019. https://doi.org/10.1002/jrs.5605.

\begin{abstract}
The molar composition of gas mixtures in fluid inclusions is one of the most important properties to reconstruct the $P V T X$ properties of geofluids. Raman spectroscopy is a powerful tool for quantitative analysis of the composition of fluids trapped in inclusions as the peak area of each species is directly linked to concentration by its Raman scattering cross section. However, previous studies proved the effect of host mineral birefringence on the shape of the stretching vibration band of liquid water, having an impact on the quantitative determination of salinity, but the influence on gas-mixture inclusions is still unknown. In this study, the Raman signals of coexisting $\mathrm{CO}_{2}, \mathrm{CH}_{4}$ and $\mathrm{N}_{2}$ in two natural fluid inclusions in quartz were collected with sample rotation on the microscope stage. Peak area ratios $\left(\mathrm{CO}_{2}{ }^{+} / \mathrm{CH}_{4}, \mathrm{CO}_{2}{ }^{+} / \mathrm{N}_{2}\right.$, and $\left.\mathrm{N}_{2} / \mathrm{CH}_{4}\right)$ showed sinusoidal variations with a period of $45^{\circ}$. On the contrary, the area ratio of the two peaks of $\mathrm{CO}_{2}\left(\mathrm{CO}_{2}{ }^{+} /\right.$ $\mathrm{CO}_{2}{ }^{-}$) and the Fermi diad splitting remained constant with sample rotation. This effect is most probably due to a combination of polarization effects as previously observed for liquid water: depolarization ratios of each gas species, birefringence of the host mineral, and polarization response curve of the spectrometer. It can be canceled placing the sample at crystal extinction position.
\end{abstract}

KEYWORDS: RAMAN SPECTROSCOPY; FLUID INCLUSIONS; GAS; BIREFRINGENCE; POLARIZATION

\section{INTRODUCTION}

Fluid inclusions are remnants of crustal or mantle fluids circulating during geological processes. The reconstruction of their physicochemical properties, density $\rho$ or molar volume $V$ and composition $X$, permits to discuss and constrain fluid source, redox conditions, fluid-rock interaction and $P T$ conditions associated to ore deposits, basin diagenesis, among others. The knowledge of the $V X$ properties of individual fluid inclusions is obtained through advanced analytical techniques like microthermometry, Raman spectroscopy or LA-ICPMS. One of the essential parameters measured during fluid inclusion investigation is the composition of the gas phase. This is however challenging, because of the very small volume of the bubble, usually enclosed in a liquid phase. The presence of major components is generally obtained by microthermometry on the basis of phase transition observations (discontinuous or continuous melting, clathrate dissociation and partial homogenization) completed by Raman spectroscopy for the identification of coexisting minor components. Microthermometry has nevertheless several limitations due to the difficulty to observe phase transitions in small inclusions, the absence of phase transition observation for low density gas mixture and/or the case of more than one or two components in the gas phase $^{[1]}$.

Raman microspectrometry is another technique that makes possible to determine gas phase composition in fluid inclusions ${ }^{[2-9]}$. The laser spot size is usually less than a few micrometers, which is about the minimal size of a gas bubble. Peak positions are directly related to the chemical nature of the gases, with a detection limit of approximately one percent. Peak positions also vary with pressure or density making possible to determine this parameter after calibration of the peak position shift with pressure and temperature ${ }^{[\mathrm{e.g} .}{ }^{10-17]}$. Peak intensities are proportional to molar concentrations taking into account the instrument response curve, cross sections, density and mixture composition ${ }^{[6-9,18-23]}$.

Birefringence is an optical property of anisotropic materials linked to polarization and responsible for double refraction in crystals. It is due to the presence of more than one refractive index in the material. Birefringence modifies the polarization 
properties of light entering anisotropic material ${ }^{[24-}$ 26]. For linearly polarized light such as laser, polarization becomes ellipsoidal when entering an anisotropic material. The only cases when light polarization remains unchanged are when it enters (i) isotropic material and (ii) anisotropic material through the face perpendicular to the optical axis, i.e. the sample is put at crystal extinction ${ }^{[24]}$. Previous studies demonstrated that host crystal orientation has an impact on the Raman signal of liquid water in fluid inclusions ${ }^{[24,27,28]}$ because of the modification of laser light polarization by the host crystal and the difference in depolarization ratio of the different Raman bands of liquid water [24]. The spectrometer grating has not a constant response curve to polarization with wavelength: some ranges are more sensitive to vertically polarized light and other ones are more sensitive to horizontally polarized light ${ }^{[29]}$. This variation is usually continuous, with an inversion point at a certain wavelength ${ }^{[24]}$. The spectrometer polarization response curve will thus vary with peak position. As a consequence, crystal hosting fluid inclusions must be put at extinction position to record a Raman spectrum of liquid water that is not affected by birefringence.

\begin{tabular}{|l|l|l|}
\hline molecule & $\boldsymbol{v} / \mathbf{c m}^{-1}$ & $\boldsymbol{\rho}$ \\
\hline $\mathbf{H}_{2}$ & 4156 & 0.070 \\
\hline $\mathbf{C H}_{4}$ & 2918 & 0 \\
\hline $\mathbf{N}_{2}$ & 2331 & 0.055 \\
\hline $\mathbf{C O}$ & 2143 & 0.104 \\
\hline $\mathbf{O}_{2}$ & 1555 & 0.115 \\
\hline $\mathbf{C O}_{2}$ & 1285 & 0.084 \\
& 1388 & 0.054 \\
\hline
\end{tabular}

Table 1: Depolarization ratio $(\rho)$ of the main vibration peak $\left(v / \mathrm{cm}^{-1}\right)$ of mainly encountered gases in natural fluid inclusions. Note. Data from Murphy et al.[32] and references therein.

Raman scattered light is usually polarized. Depolarization ratio $(\rho)$ defines the ratio between horizontal and vertical polarization components of each Raman emission line ${ }^{[31,32]}$. It varies between zero (polarized) and 0.75 (depolarized). Murphy et al. ${ }^{[30]}$ summarized old literature data on depolarization ratio of gases. $\mathrm{CH}_{4}$ symmetric vibration mode at $\sim 2917 \mathrm{~cm}^{-1}$ is completely polarized $(\rho=0)$ as for all spherically symmetric molecules such as molecules of tetrahedral symmetry like $\mathrm{CH}_{4}{ }^{[32]}$. On the contrary, the vibration modes of $\mathrm{H}_{2}, \mathrm{~N}_{2}, \mathrm{CO}, \mathrm{O}_{2}$, and $\mathrm{CO}_{2}$ are partially depolarized (Table 1) from about 5 to 12
$\%$. For liquid water, the depolarization ratio at the two positions of interest $\left(3260 \mathrm{~cm}^{-1}\right.$ and $3425 \mathrm{~cm}^{-1}$ ) were of 8 and $20 \%$, respectively ${ }^{[24,33]}$. Considering that the range of wavelength of gas species is larger than that of liquid water, and so that the variations of the polarization properties of the grating will be larger too, it is expected that even small differences in depolarization ratio could yield intensity variations with crystal orientation because of birefringence.

The objective of this study was to determine if there was an effect of the birefringence of the host mineral on the analysis of the gas phase of fluid inclusions by Raman microspectrometry. Two natural fluid inclusions hosted in quartz and containing a gas mixture in various proportions of $\mathrm{CO}_{2}, \mathrm{CH}_{4}$ and $\mathrm{N}_{2}$ were analyzed. The Raman spectra of the gas phase were recorded rotating the quartz sample around its optical extinction position. Gas peak area ratio were measured at different angles to extinction position and then compared. The significance of the observations were discussed yielding practical recommendations to analyze the gas phase of natural fluid inclusions.

\section{MATERIAL AND METHODS}

\section{Natural fluid inclusion samples}

The first case was made on a fluid inclusion from a quartz sample from the quartz-vein type deposit W$\mathrm{Cu}-\mathrm{Sn}$ deposit of Panasqueira (Portugal). Several quartz generations are described associated or not with ore deposition ${ }^{[37]}$. The about $100 \mu \mathrm{m}$ twophase liquid-vapor (LV) negative-crystal shape studied fluid inclusion has a vapor bubble in the order of $10 \mathrm{vol} \%$, that contains a gas mixture mainly composed of $\mathrm{CO}_{2}$, with minor amounts of $\mathrm{CH}_{4}$ and $\mathrm{N}_{2}{ }^{[38,39]}$ (Figure 1a). The sample was cut without regarding crystal orientation.

Quartz sample Mu9.1.1 is a prismatic crystal from an Alpine tension fissure of the external part (Bundstock NW, Wildhorn Helvetic nappe, Switzerland) of the Central Alps. The sample belongs to the so-called $\mathrm{CH}_{4}$-zone ${ }^{[34]}$ and contains two types of coexisting two-phase fluid inclusions at room temperature: (i) aqueous liquid-rich with a $<10$ vol.\% $\mathrm{CH}_{4}$-rich gas bubble and (ii) $\mathrm{CH}_{4}$-rich with a very thin rim of aqueous liquid around a $>80$ vol.\% gas phase made of liquid $\mathrm{CH}_{4}$ with minor amounts of $\mathrm{CO}_{2}$ issued from redox reactions during prograde metamorphism ${ }^{[35,36]}$. The about $10 \mu \mathrm{m}$ negative-crystal shape fluid inclusion studied in the 
present work corresponds to the latter situation (Figure 1b). The host euhedral quartz crystal was cut parallel to the $c$-axis and parallel to one of the prism faces.

\section{Raman spectroscopy}

The Raman spectra of the two natural fluid inclusions were acquired using a LabRAM microspectrometer (Horiba Jobin Yvon) with a focal length of $300 \mathrm{~mm}$, equipped with a 1800 gr.mm ${ }^{-1}$ grating and a $50 \times$ objective (Olympus, N.A. 0.50). Excitation was provided by an $\mathrm{Ar}^{+}$laser (Stabilite 2017, Spectra-Physics) at $514.5 \mathrm{~nm}$ and a power of $200 \mathrm{~mW}$ corresponding to about $20 \mathrm{~mW}$ at sample. Spectral resolution was about $4 \mathrm{~cm}^{-1}$ at $1000 \mathrm{~cm}^{-1}$. The response curves of the spectrometer among vertical and horizontal polarization directions were recorded using a non polarized white lamp (HCA Calibration Accessory, Kaiser Optical Systems) as described in Caumon et al. ${ }^{[24]}$. The spectrometer had a strongly polarized response curve, being more sensitive along vertical polarization direction, from $67 \%$ at $1000 \mathrm{~cm}^{-1}$ up to $77 \%$ at $3000 \mathrm{~cm}^{-1}$ (Figure 2).

The host mineral was set at extinction position on the rotating stage of the microscope using crossed polarizers; this position corresponds to the starting point of the experiment. The Raman spectrum of the gas phase was recorded every $5^{\circ}$ from extinction $\left(0^{\circ}\right)$ to $100^{\circ}$ with 4 accumulations of 2 , 10 or $20 \mathrm{~s}$ depending on gas peak intensity. Acquisitions were repeated 6 times. For
Panasqueira sample, the contribution of atmospheric $\mathrm{N}_{2}$ was determined by recording $\mathrm{N}_{2}$ signal when focused outside the inclusion using the same acquisition parameters as for the inclusion (same focus, same parameters). $\mathrm{N}_{2}$ peak area from the inclusion was calculated by subtracting atmospheric $\mathrm{N}_{2}$ peak area from the one measured when focused in the gas phase. Peak area was determined by integrating peak area between two points after subtraction of a straight baseline between these anchorage points. The width of the integrated area was constant for all spectra of a set of measurements.

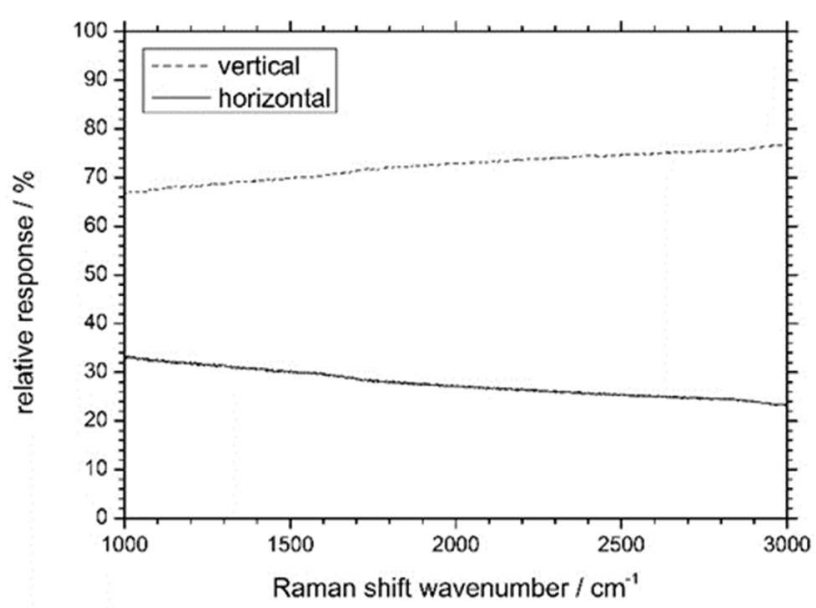

Figure 2: relative response curve of the spectrometer among horizontal (solid line) and vertical (dash line) polarization direction. Raman shift wavenumbers were calculated from a virtual excitation at $514.53 \mathrm{~nm}$.
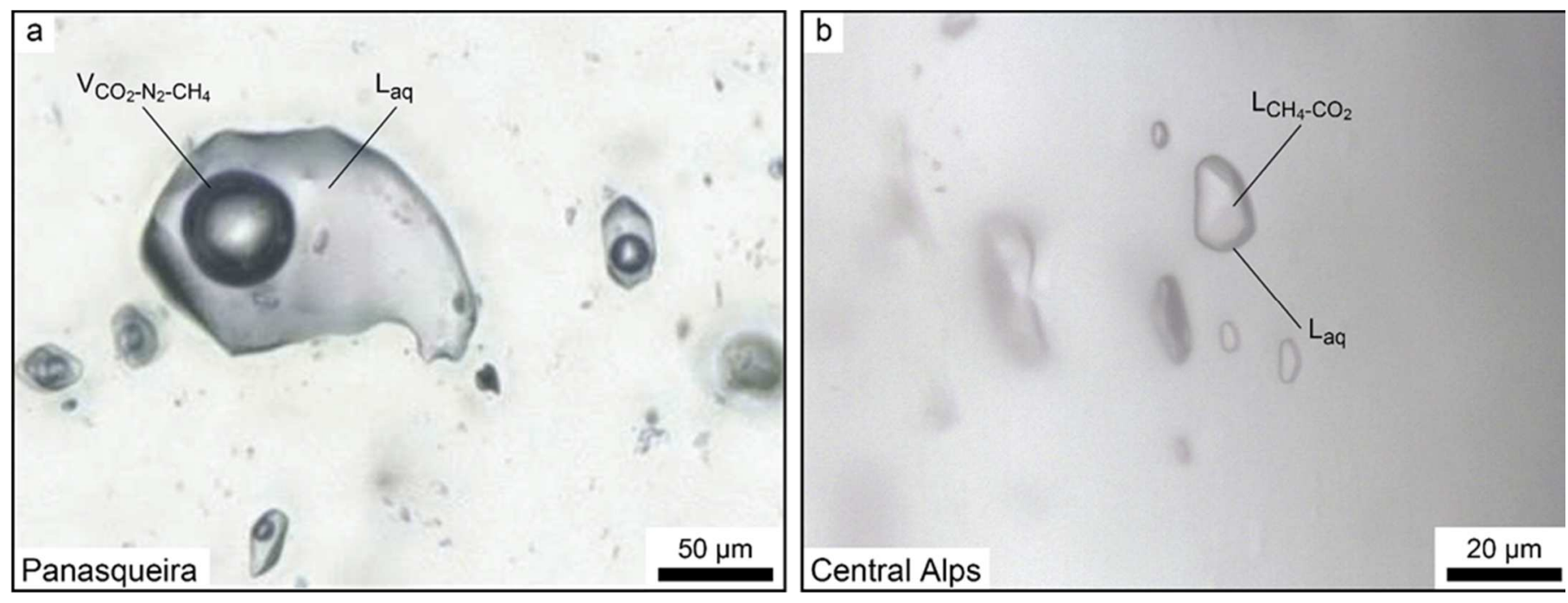

Figure 1: microphotographs of the two investigated fluid inclusions and phase state at room temperature: (a) Panasqueira sample and (b) Alps sample.

The Raman signal of $\mathrm{CO}_{2}$ consists in a Fermi doublet ${ }^{[40-42]}$ with two main peaks at $1286 \mathrm{~cm}^{-1}\left(v^{-}\right.$
, noted $\left.\mathrm{CO}_{2}^{-}\right)$and $1384 \mathrm{~cm}^{-1}\left(\mathrm{v}^{+}\right.$, noted $\left.\mathrm{CO}_{2}{ }^{+}\right) . \mathrm{N}_{2}$ peak is found at $2331 \mathrm{~cm}^{-1}$ and $\mathrm{CH}_{4}$ at $2917 \mathrm{~cm}^{-1}$ 
[2]. The following peak area ratio were calculated: $\mathrm{CO}_{2}^{+} / \mathrm{CH}_{4}, \mathrm{CO}_{2}^{+} / \mathrm{N}_{2}, \mathrm{CO}_{2}^{+} / \mathrm{CO}_{2}^{-}$and $\mathrm{N}_{2} / \mathrm{CH}_{4}$ and presented as a percentage of variation from extinction position $\left(0^{\circ}\right)$. Uncertainty on peak area ratio calculated from the 6 repeated spectra was less than $1 \%$ of absolute value. Final uncertainty should also include uncertainty on sample position (rotation) and temperature (laser heating) but cannot be quantified. It was estimated to $2 \%$ in relative peak area ratio scale regarding the variation of $\mathrm{CO}_{2}{ }^{+} / \mathrm{CO}_{2}^{-}$in Figure 5Erreur ! Source du renvoi introuvable.

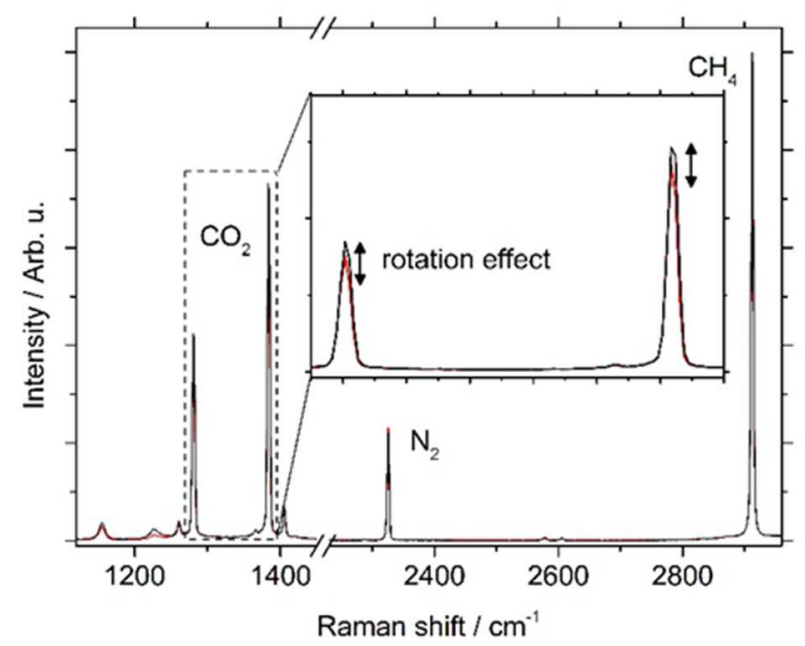

Figure 3: Raman spectra of the Panasqueira natural fluid inclusion at crystal extinction position (black line) and at $45^{\circ}$ (red line). Spectra are normalized to $\mathrm{CH}_{4}$ maximum intensity.

\section{RESULTS}

Two normalized spectra of Panasqueira sample are presented in Figure 3 showing a variation in peak intensity with rotation. The relative variation of peak area ratios are presented in Figure 4 (Panasqueira sample) and in Figure 5Erreur! Source du renvoi introuvable. (Alps sample). A sine evolution with rotation is clearly observed. The maximum of variation is observed at $45^{\circ}$. At $90^{\circ}$, crystals are again at extinction and peak area ratio are comparable to those measured at $0^{\circ}$. The strongest variation is observed for $\mathrm{CO}_{2}^{+} / \mathrm{CH}_{4}$. There is no detectable variation of $\mathrm{CO}_{2}{ }^{+} / \mathrm{CO}_{2}{ }^{-}$ratio except a few percents of continuous deviation, probably due to a small effect of fluid heating by laser, as peak intensity ratio in Fermi doublet is sensitive to density ${ }^{[17]}$. No change in Fermi diad splitting with rotation is observed at this low spectral resolution. In Panasqueira sample (Figure 4Erreur! Source du renvoi introuvable.), relative variation is strongly negative for $\mathrm{CO}_{2}{ }^{+} /$ $\mathrm{CH}_{4}$ (down to $-10 \%$ ) and $\mathrm{CO}_{2}{ }^{+} / \mathrm{N}_{2}$ (down to $-8 \%$ ) and so slightly negative for $\mathrm{N}_{2} / \mathrm{CH}_{4}$ (max. $-3 \%$ ). In Alps sample, variation of $\mathrm{CO}_{2}{ }^{+} / \mathrm{CH}_{4}$ is strongly positive (up to $12 \%$ ) whereas it is strongly negative in Panasqueira sample.

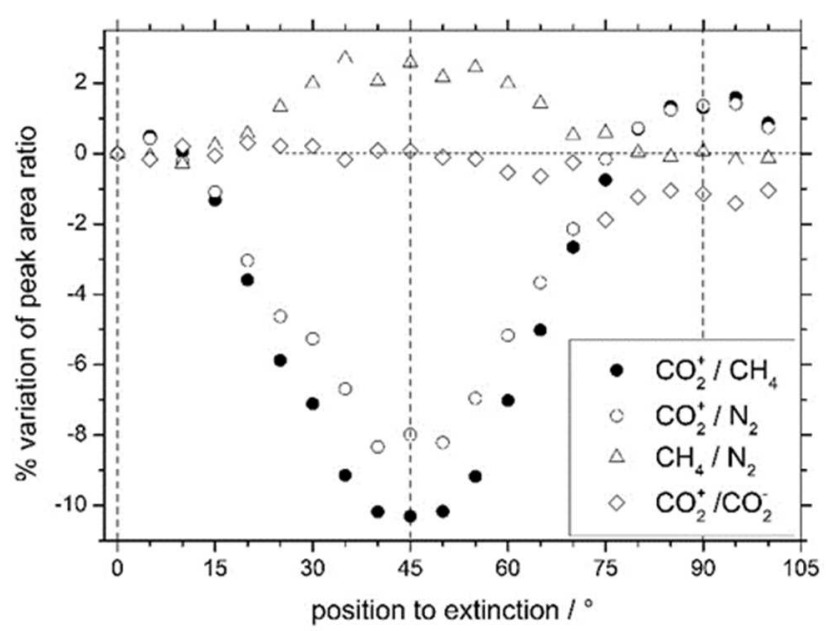

Figure 4: variation (\%) of peak area ratio as a function of host crystal orientation, Panasqueira sample.

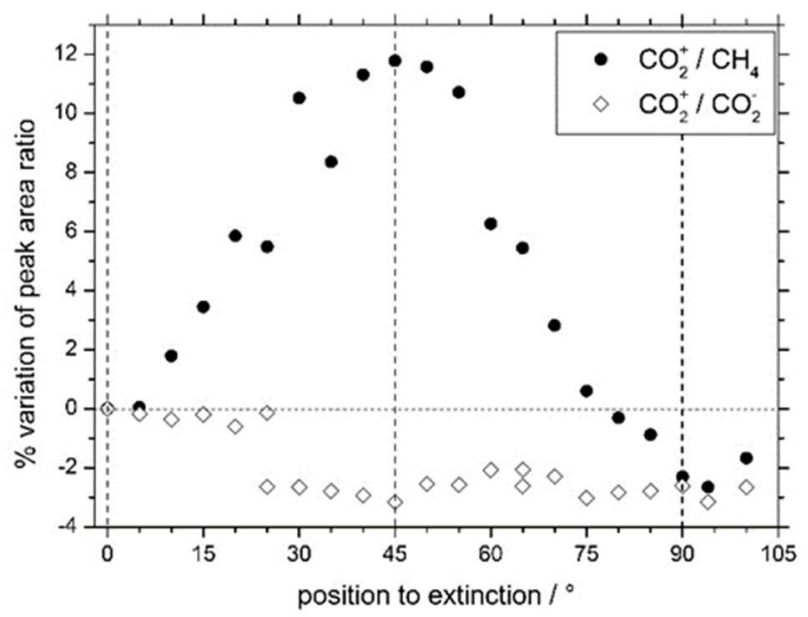

Figure 5: variation (\%) of peak area ratio as a function of host crystal orientation, Alps sample.

\section{DISCUSSION}

When rotating the sample, several factors may affect peak intensities because of birefringence ${ }^{[24]}$. (i) depolarization ratio of the Raman peaks, (ii) polarization properties of the grating at peak position and (iii) crystal orientation to main axis. The combination of these three effects yields to what is observed in Figure 4 and Figure 5Erreur ! Source du renvoi introuvable.. First, the highest difference in depolarization ratio is the one of $\mathrm{CH}_{4}$ with other gases (Table 1). Second, the response curve of the grating to vertically and horizontally polarized light evolves continuously with 
wavelength (Figure 2). Thus, peaks that are far from each other will encountered the highest differences of the response curve of the grating: the maximum effect is observed for $\mathrm{CH}_{4}$ and $\mathrm{CO}_{2}$ with the highest difference in depolarization ratio ( 0 and 0.084 respectively) and with peak positions far from each other $\left(2917 \mathrm{~cm}^{-1}\right.$ and $1384 \mathrm{~cm}^{-1}$, respectively). The lowest variation is observed for $\mathrm{CH}_{4}$ and $\mathrm{N}_{2}$ that are close to each other on the Raman spectrum $\left(2917 \mathrm{~cm}^{-1}\right.$ and $2331 \mathrm{~cm}^{-1}$, respectively) with a slightly lower difference in depolarization ratio (0 and 0.055$)$. Finally, crystal orientation may affect the intensity and the direction of the polarization variation as a function of the angle of the sample plane to $c$ axis. The Alps sample was cut parallel to $c$ axis, i.e. the orientation with highest birefringence effect. The two samples in this study show similar amplitude of variation but with opposite direction. It is probably due to the orientation of the crystal section. Birefringence effect might also increase with inclusion depth due to the increase of the optical path length ${ }^{[27]}$. However this effect is hardly evaluable as the signal-to-noise ratio strongly decreases with depth too.

Gas phase composition in molar relative abundance can be determined by Raman spectroscopy measuring peak area ratio corrected by Raman cross-sections and the response curve of the spectrometer $^{[6-9]}$ neglecting any density or composition effect ${ }^{[19]}$. Here we observed a relative variation up to about $10 \%$ in peak areas with rotation. The impact on molar proportions will vary with composition. For example, in Panasqueira sample, gas phase is dominated by $\mathrm{CO}_{2}$. Once the peak areas are converted into molar proportions, the final composition will only vary of $2 \%$ with rotation (76-78 mol\% $\mathrm{CO}_{2}, 15-17 \mathrm{~mol}_{2} \mathrm{~N}_{2}$ and 5$7 \mathrm{~mol} \% \mathrm{CH}_{4}$ ). In the Alps sample, the $\mathrm{CH}_{4}-\mathrm{CO}_{2}$ gas phase is mainly composed of $\mathrm{CH}_{4}(90 \%)$ with a variation of $\pm 1 \mathrm{~mol} \%$ with rotation, in agreement with microthermometry ${ }^{[35]}$. A variation of a few percents is of the same order of magnitude as the expected uncertainty on this kind of measurements using Raman cross sections which uncertainties are unknown and without considering density or composition effect on cross section ${ }^{[19-21]}$.

\section{CONCLUSION}

The effect of host crystal orientation in measuring gas phase composition of natural fluid inclusions by Raman spectroscopy was investigated. An effect similar to the one previously observed for liquid water ${ }^{[24,27,28]}$ was measured. To avoid a modification of the Raman signal by polarization effect, host crystal must be placed at extinction position. However, the impact on molar proportions is low, i.e. only a few percents, depending on gas depolarization ratio, molar proportions, crystal orientation and polarization response curve of the spectrometer. In practice it becomes negligible when the gas phase is dominated (>90\%) by one gas, considering this effect is probably lower than uncertainty on Raman cross-sections which are supposed to be composition and density dependent ${ }^{[19-22]}$.

\section{ACKNOWLEDGMENTS}

This work was supported by INSU-CESSUR (CNRS) grant. The authors are very grateful to Marie-Christine Boiron for providing Panasqueira sample. Dr. Márta Berkesi and an anonymous reviewer are thanked for their helpful and constructive reviews.

\section{REFERENCES}

[1] E. Roedder, Fluid inclusions, Mineralogical Society of America, 1984, vol. 12.

[2] M. L. Frezzotti, F. Tecce, A. Casagli, J. Geochem. Explor. 2012, 112, 1.

[3] J. D. Pasteris, B. Wopenka, J. C. Seitz, Geochim. Cosmochim. Acta 1988, 52, 979.

[4] J. D. Pasteris, J. C. Seitz, B. Wopenka, I.-M. Chou, Microbeam Anal. 1990, 228.

[5] B. Wopenka, J. D. Pasteris, Anal. Chem. 1987, 59, 2165.

[6] B. Wopenka, J. D. Pasteris, Appl. Spectrosc. 1986, 40, 144.

[7] J. Dubessy, B. Poty, C. Ramboz, Eur. J. Mineral. 1989, $1,517$.

[8] E. A. J. Burke, Lithos 2001, 55, 139.

[9] V. G. Baonza, F. Rull, J. Dubessy, in Raman Spectroscopy Applied to Earth Sciences and Cultural Heritage, (Eds: J. Dubessy, M.-C. Caumon, F. Rull), The European Mineralogical Union and the Mineralogical Society of Great Britain, London, 2012, vol. 12, pp. 279320.

[10] M.-C. Caumon, P. Robert, E. Laverret, A. Tarantola, A. Randi, J. Pironon, J. Dubessy, J.-P. Girard, Chem. Geol. 2014, 378-379, 52.

[11] W. Lu, I. M. Chou, R. C. Burruss, Y. Song, Geochim. Cosmochim. Acta 2007, 71, 3969.

[12] H. M. Lamadrid, L. R. Moore, D. Moncada, J. D. Rimstidt, R. C. Burruss, R. J. Bodnar, Chem. Geol. 2017, 450, 210.

[13] X. Wang, I. M. Chou, W. Hu, R. C. Burruss, Q. Sun, Y. Song, Geochim. Cosmochim. Acta 2011, 75, 4080.

[14] Y. Kawakami, J. Yamamoto, H. Kagi, Appl. Spectrosc. 2003, 57, 1333.

[15] A. Hacura, Phys. Lett. Sect. Gen. At. Solid State Phys. 1997, 227, 237.

[16] R. B. Wright, C. H. Wang, J. Chem. Phys. 1973, 58, 2893. 
[17] Y. Garrabos, R. Tufeu, B. L. Neindre, G. Zalczer, D. Beysens, J. Chem. Phys. 1980, 72, 4637.

[18] H. W. Schrötter, H. W. Klöckner, in Raman Spectroscopy of Gases and Liquids, (Ed: A. Weber), Springer Berlin Heidelberg, Berlin, 1979, vol. 11, pp. 123-166.

[19] V.-H. Le, in XIII GeoRaman, Catania, Italy, 2018, p. 96.

[20] J. C. Seitz, J. D. Pasteris, I. M. Chou, Am. J. Sci. 1993, 293, 297.

[21] J. C. Seitz, J. D. Pasteris, I. M. Chou, Am. J. Sci. 1996, 296, 577.

[22] H. M. Lamadrid, M. Steele-MacInnis, R. J. Bodnar, J. Raman Spectrosc. 2018, 49, 581.

[23] J. Fang, I.-M. Chou, Y. Chen, J. Raman Spectrosc. 2018, 49, 710.

[24] M.-C. Caumon, A. Tarantola, R. Mosser-Ruck, J. Raman Spectrosc. 2015, 46, 969.

[25] P. Bordet, Précis d'optique cristalline appliquée à l'identification des minéraux, Masson et Cie, 1968.

[26] F. D. Bloss, An introduction to the methods of optical crystallography, Saunders College Publishing, 1961.

[27] M. Baumgartner, R. J. Bakker, Mineral. Petrol. 2009, $95,1$.

[28] J. Dubessy, T. Lhomme, M. C. Boiron, F. Rull, Appl. Spectrosc. 2002, 56, 99.

[29] J. Dubessy, M.-C. Caumon, F. Rull, S. Sharma, in Raman Spectroscopy applied to Earth Sciences and Cultural Heritage, (Eds: J. Dubessy, M.-C. Caumon, F. Rull), The European Mineralogical Union and the Mineralogical Society of Great Britain \& Ireland, London, 2012, vol. 12, pp. 83-165.

[30] W. F. Murphy, W. Holzer, H. J. Bernstein, Appl. Spectrosc. 1969, 23, 211.

[31] G. Placzek, The Rayleigh and Raman Scattering, Lawrence Radiation Laboratory, 1959, vol. 526.

[32] D. A. Long, Raman spectroscopy, McGraw-Hill, NewYork, 1977.

[33] S. R. Pattenaude, L. M. Streacker, D. Ben-Amotz, J. Raman Spectrosc. 2018, 49, 1860.

[34] F. Noronha, A. Doria, J. Dubessy, B. Charoy, Miner. Deposita, DOI:10.1007/BF00196084.

[35] M. Cathelineau, C. Marignac, J.-M. Rolland, M.-C. Boiron, M. Dejean, E. Carocci, in ECROFI 2017, Nancy, 2017, p. 98.

[36] E. Carocci, C. Marignac, M. Cathelineau, L. Truche, A. Lecomte, F. Pinto, Minerals 2019, 9, 9.

[37] J. Mullis, J. Dubessy, B. Poty, J. O’Neil, Geochim. Cosmochim. Acta 1994, 58, 2239.

[38] A. Tarantola, J. Mullis, T. Vennemann, J. Dubessy, C. de Capitani, Chem. Geol. 2007, 237, 329.

[39] A. Tarantola, J. Mullis, D. Guillaume, J. Dubessy, C. De Capitani, M. Abdelmoula, Lithos 2009, 112, 497.

[40] A. Fall, B. Tattitch, R. J. Bodnar, Geochim. Cosmochim. Acta 2011, 75, 951.

[41] H. R. Gordon, T. K. McCubbin, J. Mol. Spectrosc. 1966, 19, 137.

[42] E. Fermi, Z. Für Phys. Hadrons Nucl. 1931, 71, 250. 